\title{
Clinicopathological correlation of epiretinal membranes and posterior lens opacification following perfluorohexyloctane tamponade
}

\author{
Paul Hiscott, Raymond M Magee, Matthew Colthurst, Noemi Lois, David Wong
}

\begin{abstract}
Backgroundlaims-Epiretinal and retrolental proliferation may occur during prolonged use of the novel tamponade agent perfluorohexyloctane $\left(\mathrm{F}_{6} \mathrm{H}_{8}\right)$. This study aims to determine whether there is any histological evidence that $\mathrm{F}_{6} \mathrm{H}_{8}$ has a role in the formation of these membranes.

Methods-Eight epiretinal membranes and three opaque posterior lens capsules were excised from patients in whom $\mathbf{F}_{6} \mathbf{H}_{8}$ had been used as a long term retinal tamponade agent. The membranes and capsules were examined employing light microscopic methods, including immunohistochemistry.

Results-The epiretinal membranes showed histological features typical of proliferative vitreoretinopathy (PVR) epiretinal membranes, but they also exhibited a dense macrophagic infiltration. In addition, three of the membranes contained multinucleated cells. Macrophages represented up to $30 \%$ of the cells present and appeared to contain large intracytoplasmic vacuoles. Similar cells were seen on the back of the posterior lens capsule in one specimen and all three capsules had posterior migration of lens epithelium.

Conclusion-The pathological findings are not simply those of PVR. The macrophage infiltration suggests that there may be a biological reaction to $\mathrm{F}_{6} \mathrm{H}_{8}$ which could reflect its surmised propensity to emulsify. Further investigations concerning the cellular response to this promising tamponade agent are warranted.

(Br F Ophthalmol 2001;85:179-183)
\end{abstract}

Ophthalmology,

Department of

Medicine, University

of Liverpool,

Liverpool, UK

P Hiscott

R M Magee

$M$ Colthurst

$\mathrm{N}$ Lois

D Wong

Correspondence to: Paul Hiscott, Unit of

Ophthalmology, Department of Medicine, University

Clinical Departments,

Duncan Building, Daulby

Street, Liverpool, L69 3GA,

UK

P.S.Hiscott@liverpool.ac.uk

Accepted for publication 22 August 2000

Silicone oil and long acting gases have been shown to be effective as internal tamponade agents for the management of difficult rhegmatogenous retinal detachments (RRD), especially those complicated by proliferative vitreoretinopathy (PVR). Both gas and silicone have a lower specific gravity than vitreous fluid and, when used as internal tamponade, they occupy the upper part of the vitreous cavity providing good support for the superior retina. However, PVR has a propensity for the inferior retina and the tamponade effect of gas and silicone oil may then be deficient when the fill is subtotal. ${ }^{1}$ Thus, there may be a specific role for a tamponade agent with a higher specific gravity than vitreous.
The semifluorinated alkanes (SFA) are a group of novel substances which have the potential to act as internal tamponade agents for the inferior fundus (reviewed by Colthurst et al). ${ }^{2}$ They are immiscible with aqueous and their interfacial tensions are comparable with the perfluorocarbon liquids (PFCL) and with silicone oil. ${ }^{2}$ At $1.3-1.35 \mathrm{~g} / \mathrm{cm}^{-3}$, SFA have a higher specific gravity than vitreous. Moreover, SFA have a lower specific gravity than PFCL and theoretically may cause less trophic effect on the retina than PFCL. Indeed, in a rabbit investigation the SFA perfluorohexyloctane $\left(\mathrm{F}_{6} \mathrm{H}_{8}\right)$ was left in the vitreous cavity for up to 3 months and appeared to be well tolerated. ${ }^{3}$ As a result of this investigation, $\mathrm{F}_{6} \mathrm{H}_{8}$ has been used clinically as a long term vitreous tamponade and the results of a multicentre pilot study on the use of $\mathrm{F}_{6} \mathrm{H}_{8}$ in a series of complicated retinal detachments have been presented recently. ${ }^{4}$

Some of the patients in the $\mathrm{F}_{6} \mathrm{H}_{8}$ pilot study developed recurrent retinal detachment with widespread PVR. Membranous proliferation was also observed on the posterior surface of the crystalline lens in a few phakic patients. Clinically, it was not possible to determine whether the epiretinal and retrolental membranes were the result (or an exacerbation) of the original disease process or a pathobiological response to the tamponade agent. To help resolve this uncertainty, we studied the histology of excised epiretinal membranes and posterior lens opacifications that had developed during prolonged $\mathrm{F}_{6} \mathrm{H}_{8}$ tamponade.

\section{Materials and methods}

EPIRETINAL MEMBRANES AND LENS CAPSULES Eight epiretinal membranes and three posterior lens opacifications were obtained from eight patients during closed pars plana microduring $\mathrm{F}_{6} \mathrm{H}_{8}$ tamponade (Table 1 ). Five of the age range was 29-87 years. The initial indication for retinal tamponade was PVR in three patients, foveal relocation (two patients), and penetrating/blunt trauma with $360^{\circ}$ iris dialysis, total retinal detachment, and expulsive haemorrhage (one patient each). $\mathrm{F}_{6} \mathrm{H}_{8}$ was the only tamponade employed in five of the eyes. In the remaining three patients, another tamponade agent had been present in the eye before $\mathrm{F}_{6} \mathrm{H}_{8}$ instillation (Table 1). The duration of $\mathrm{F}_{6} \mathrm{H}_{8}$ fill varied from 4 to 21 weeks. PVR was the indication for reoperation in all eight patients. 
Table 1 Clinical details of the eight patients with $\mathrm{F}_{6} \mathrm{H}_{8}$ tamponade

\begin{tabular}{|c|c|c|c|c|c|c|c|c|}
\hline $\begin{array}{l}\text { Patient } \\
\text { number }\end{array}$ & Age & Sex & $\begin{array}{l}\text { Aetiology of retinal } \\
\text { disease }\end{array}$ & Initial retinal status & Tamponade agent & $\begin{array}{l}\text { Duration of } \\
F_{6} H_{8} \text { fill }\end{array}$ & $\begin{array}{l}\text { Retinal status on } \\
F_{6} H_{8} \text { removal }\end{array}$ & Specimens \\
\hline 1 & 54 & Male & RRD & PVR grade $\mathrm{CP} 4$ & $\mathrm{~F}_{6} \mathrm{H}_{8}$ only & 8 weeks & PVR grade CP† & ERM \\
\hline 2 & 87 & Female & Pseudophakic RD & PVR grade CP4 & $\mathrm{F}_{6} \mathrm{H}_{8}$ only & 10 weeks & PVR grade CP† & ERM \\
\hline 3 & 29 & Male & $\mathrm{B} / \mathrm{P}$ trauma & $360^{\circ}$ iris dialysis & $\mathrm{F}_{6} \mathrm{H}_{8}$ only & 9 weeks & PVR grade CP† & ERM \\
\hline 4 & 65 & Female & Expulsive haemorrhage & Totally detached ${ }^{\star}$ & SO 2 days, then $\mathrm{F}_{6} \mathrm{H}_{8}$ & 10 weeks & PVR grade CP12 & ERM \\
\hline 5 & 87 & Female & Foveal relocation & $180^{\circ}$ retinotomy & $\mathrm{F}_{6} \mathrm{H}_{8}$ only & 7 weeks & PVR grade CP8 & $\mathrm{ERM}+\mathrm{PLC}$ \\
\hline 6 & 81 & Female & Foveal relocation & $180^{\circ}$ retinotomy & $\mathrm{F}_{6} \mathrm{H}_{8}$ only & 9 weeks & PVR grade CP8 & $\mathrm{ERM}+\mathrm{PLC}$ \\
\hline 7 & 32 & Female & RRD & Totally detached & $\mathrm{SF}_{6} 1$ week, then $\mathrm{F}_{6} \mathrm{H}_{8}$ & 4 weeks & PVR grade CP4 & ERM \\
\hline 8 & 59 & Male & MM local resection & PVR grade CP8 & SO 12 weeks, then $\mathrm{F}_{6} \mathrm{H}_{8}$ & 21 weeks & PVR grade CP† & $\mathrm{ERM}+\mathrm{PLC}$ \\
\hline
\end{tabular}

PVR = proliferative vitreoretinopathy (grading according to the system of Machemer et al. ${ }^{20}$; RRD = rhegmatogenous retinal detachment; ERM = epiretinal mem-

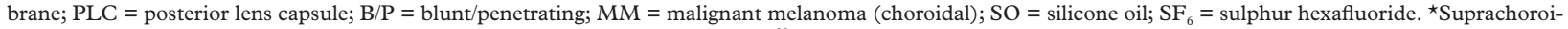
dal haemorrhage. †Macular pucker (contraction type 1: focal starfold at macula). ${ }^{20}$

\section{LIGHT MICROSCOPY AND}

IMMUNOHISTOCHEMISTRY

All specimens were either processed into glycol methacrylate resin following acetone treatment (three membranes and two capsules) or fixed in $10 \%$ neutral buffered formalin, dehydrated in graded concentrations of ethanol and embedded in paraffin wax (five membranes and one capsule). ${ }^{5}$ Sections of wax embedded tissue were cut and dewaxed. These sections, together with resin embedded tissue sections, were stained with haematoxylin and eosin. Further sections were stained with periodic acid Schiff (PAS). A record was made of the presence or absence of retinal inner limiting lamina, blood vessels, connective tissue elements (including fibroblastic cells-that is, spindle-shaped or kite-shaped cells), cells of retinal origin and inflammatory cells (neutrophils, plasma cells, lymphocytes, macrophages) in the epiretinal membranes.

Since it is difficult to differentiate morphologically between ectopic glial and retinal pigment epithelial (RPE) cells and between macrophagic RPE and macrophages of monocyte origin, immunohistochemical methods were used to distinguish between these cell types. ${ }^{67}$ The antibodies employed were mouse monoclonal antibodies to glial fibrillary acidic (GFAP), a broad spectrum of cytokeratins and CD68 respectively (all from Dako, Ely, UK). Immunoreactive sites were visualised red (using 3-amino-9-ethylcarbazole or fast red). Controls were conducted as previously described. ${ }^{6}$ Sections were counterstained with Mayer's haematoxylin and examined by bright field microscopy. The distribution and approximate proportion of the cell types were recorded as previously described. ${ }^{67}$

Table 2 Vacuolated macrophages in $\mathrm{F}_{6} \mathrm{H}_{8}$ related PVR epiretinal membranes

\begin{tabular}{llll}
\hline & ERM from patient & $\begin{array}{l}\text { Proportion of } \\
\text { vacuolated } \\
\text { macrophages as } \\
\text { \%of total cells }\end{array}$ & $\begin{array}{l}\text { Multinucleated } \\
\text { giant cells (\% of } \\
\text { total cells) }\end{array}$ \\
\hline 1 & macrophages & 10 & $+(5 \%)$ \\
2 & Isolated cells, foci and layers & 10 & $+(5 \%)$ \\
$3^{\star} \dagger$ & Isolated cells, foci & 30 & $+(5 \%)$ \\
$4^{\star}$ & Isolated cells, foci and layers & 5 & - \\
5 & Isolated cells, foci & 20 & - \\
6 & Isolated cells, foci and layers & 20 & - \\
$7 \dagger$ & Isolated cells, layers & 10 & - \\
8 & Isolated cells, foci and layers & 30 & \\
\hline
\end{tabular}

ERM = epiretinal membrane.

${ }^{\star}$ Specimen contained capillaries.

†No retinal inner limiting lamina contained in specimen.

+ present; - absent.

\section{Results}

EPIRETINAL MEMBRANES

All eight epiretinal membranes were fibrocellular in nature. Six were avascular and two contained capillaries (Table 2, Fig 1). Fragments of retinal inner limiting lamina were present in six membranes (Table 2, Fig 1). Variable amounts of intracellular and extracellular pigment was observed in all eight specimens (Figs 1 and 2). All the membranes contained glial and RPE cells, which were arranged in foci, layers, and/or distributed as isolated cells in the tissue (Fig 1). The collagenous tissue contained fibroblastic cells and some of these cells were immunoreactive for cytokeratins (Fig 2). Scattered lymphocytes were present in six membranes and occasional plasma cells were observed in one. Neutrophils were not found in any specimen.

All of the membranes contained CD68 positive, cytokeratin negative macrophages (Table 2, Figs 1 and 2). These cells exhibited large intracytoplasmic vacuoles which tended to compress the cytoplasm to a thin peripheral rim and displace the nucleus to the cell periphery (Fig 1). The vacuolated macrophages represented between $5 \%$ and $30 \%$ of the total cell population of the membranes (Table 2). They were inclined to form clusters or layers in the membranes, although each membrane also contained isolated vacuolated macrophages scattered through the tissue (Table 2, Fig 1). In addition to the vacuolated macrophages, three of the epiretinal membranes contained multinucleated giant cells (Table 2, Figs 1 and 2), many of which contained vacuoles similar to those seen in the macrophages. The multinucleated cells also showed CD68 positivity and represented a relatively small proportion (5\%) of the total cell population in each membrane (Table 2, Fig 2).

POSTERIOR LENS CAPSULES

All three of the samples consisted of segments of lens capsule with lens epithelium on one surface (Table 3). The epithelium formed a monolayer of cuboidal cells in two of the specimens. In the third, the epithelial cells appeared as a thin layer of fibroblastic cells (Table 3, Fig 2). In this third specimen, there also was a pigmented, cellular "retrolental membrane" on the posterior surface of the capsular material (Table 3, Fig 2). This membrane consisted of layers of vacuolated macrophages, similar to those seen in the epiretinal membranes, together with cytokeratin positive fibroblastic 
cells (Fig 2). Glia, lymphocytes, plasma cells, neutrophils, and giant cells were not seen in this specimen.

\section{Discussion}

Our results show that PVR membranes forming in the presence of $\mathrm{F}_{6} \mathrm{H}_{8}$ have many of the architectural features of PVR membranes evolving in the absence of a tamponade agent. ${ }^{8}$ Thus the membranes examined in this study were fibrocellular and, apart from two membranes with a few capillaries, avascular. Furthermore, the majority of the specimens contained fragments of inner limiting lamina from the retina. Moreover, as also is typical for PVR, the epiretinal membranes contained a mixed cell population. This population comprised glia, RPE, fibroblasts (including fibroblastic cells of RPE origin - that is, cytokeratin positive fibroblast like cells), and inflammatory cells.

Characteristically, inflammatory cells are not prominent components of PVR epiretinal membranes. ${ }^{78}$ Hence, small numbers of macrophages can be found in about a third of PVR epiretinal membranes arising in the absence of
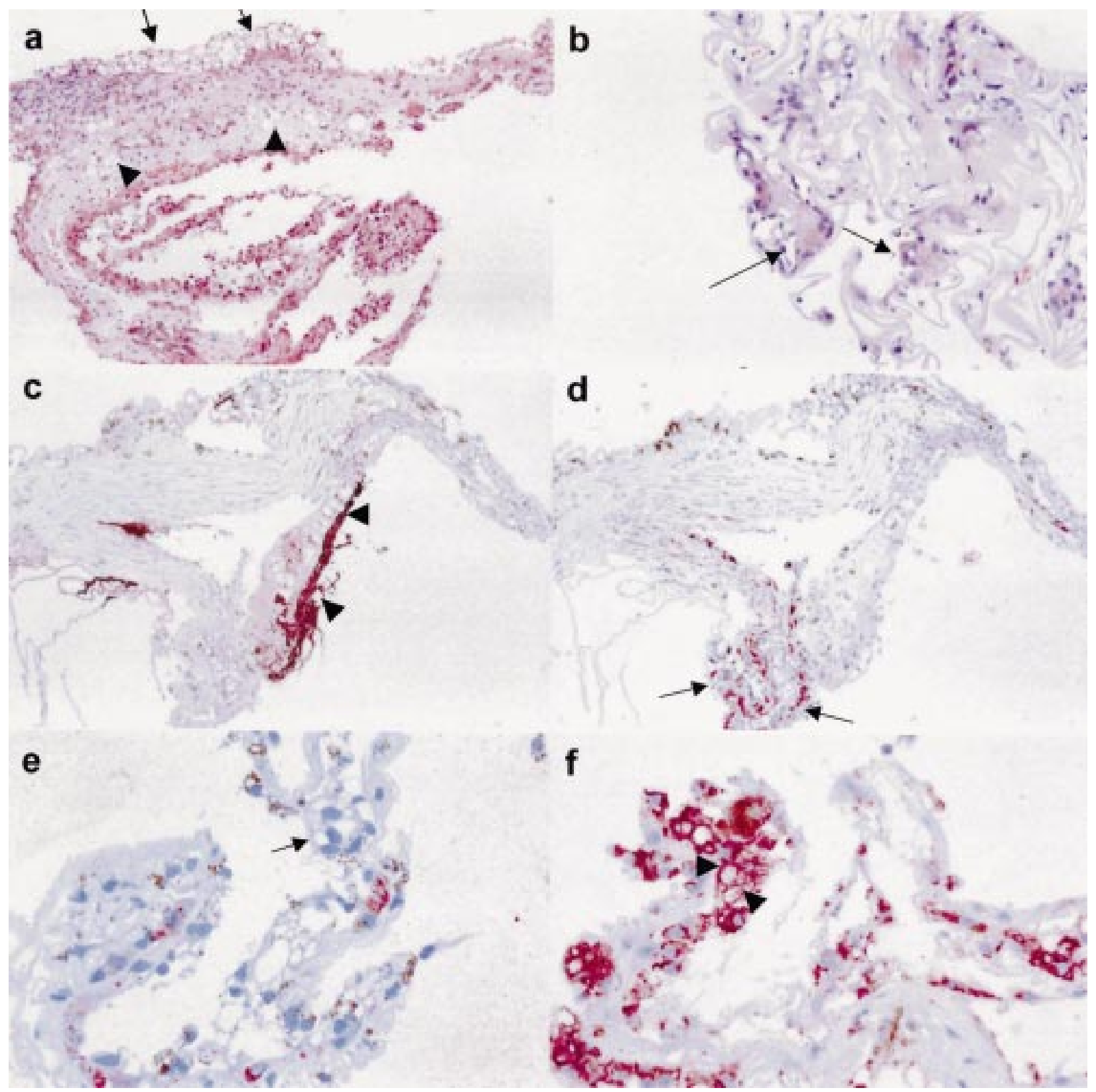

Figure 1 Photomicrographs of sections through epiretinal membranes formed in the presence of $F_{6} H_{s^{-}}$(a) and (b) Stained with haematoxylin and eosin. In (a), there is a prominent layer of vacuolated cells at the surface of the specimen (arrows) and similar cells (arrowheads) appear within the fibrous component of this vascularised membrane. (b) This specimen contains abundant folded inner limiting lamina but also exhibits vacuolated multinucleated giant cells (arrows). (c) to $(f)$ Sections from the same specimen stained red by immunohistochemistry (haematoxylin counterstain) for glial fibrillary acidic protein (GFAP; c), cytokeratins (d and e) and CD68 ( $f$ ). In (c), a prominent GFAP positive layer is seen (arrowheads). (d) Shows an area (arrows) containing a layered mixture of cytokeratin reactive cells and cytokeratin negative vacuolated cells near the glial layer. (e) A higher power view of another cytokeratin stained section in the mixed cell area depicted in (d) reveals that the layers of cytokeratin negative vacuolated cells (which include a multinucleated cell: arrow) appear to outnumber the epithelial cells. Note also the presence of brown pigment. (f) A section deeper into the same area as (e) shows that the vacuolated cells seen in (e) are CD68 positive. Many of these macrophages appear to have only a thin rim of cytoplasm around the vacuole (arrowhead). Magnification: $a \times 50 ; b \times 100 ; c$ and $d \times 60$; $e$ and $f \times 300$. 
Table 3 Histopathological features of the three posterior lens capsule opacifications arising in the presence of $\mathrm{F}_{6} \mathrm{H}_{8}$

\begin{tabular}{llll}
\hline & $\begin{array}{l}\text { Posterior migration } \\
\text { of lens epithelial } \\
\text { cells }\end{array}$ & $\begin{array}{l}\text { Fibroblastic metaplasia of lens } \\
\text { epithelial cells }\end{array}$ & Retrolental membrane \\
\hline 5 & + & - & - \\
6 & + & - & - \\
8 & + & + & $++^{\star}$ \\
\hline
\end{tabular}

+ present; - absent.

* The retrolental membrane comprised vacuolated macrophages and cytokeratin positive fibroblastic cells (Fig 2). a tamponade agent, ${ }^{7}$ although epiretinal membranes of other aetiological types may contain a more prominent macrophage component. ${ }^{9}$ In contrast, all of the PVR membranes evolving in the presence of $\mathrm{F}_{6} \mathrm{H}_{8}$ contained abundant macrophages and in two of these specimens macrophages represented about $30 \%$ of the cells. These cells expressed CD68 and were cytokeratin negative, indicating that they were macrophages rather than RPE cells which had "transdifferentiated" to a macrophage-like phenotype. ${ }^{10} 11$

Immunohistochemical studies show that macrophage-like RPE are occasionally ob-

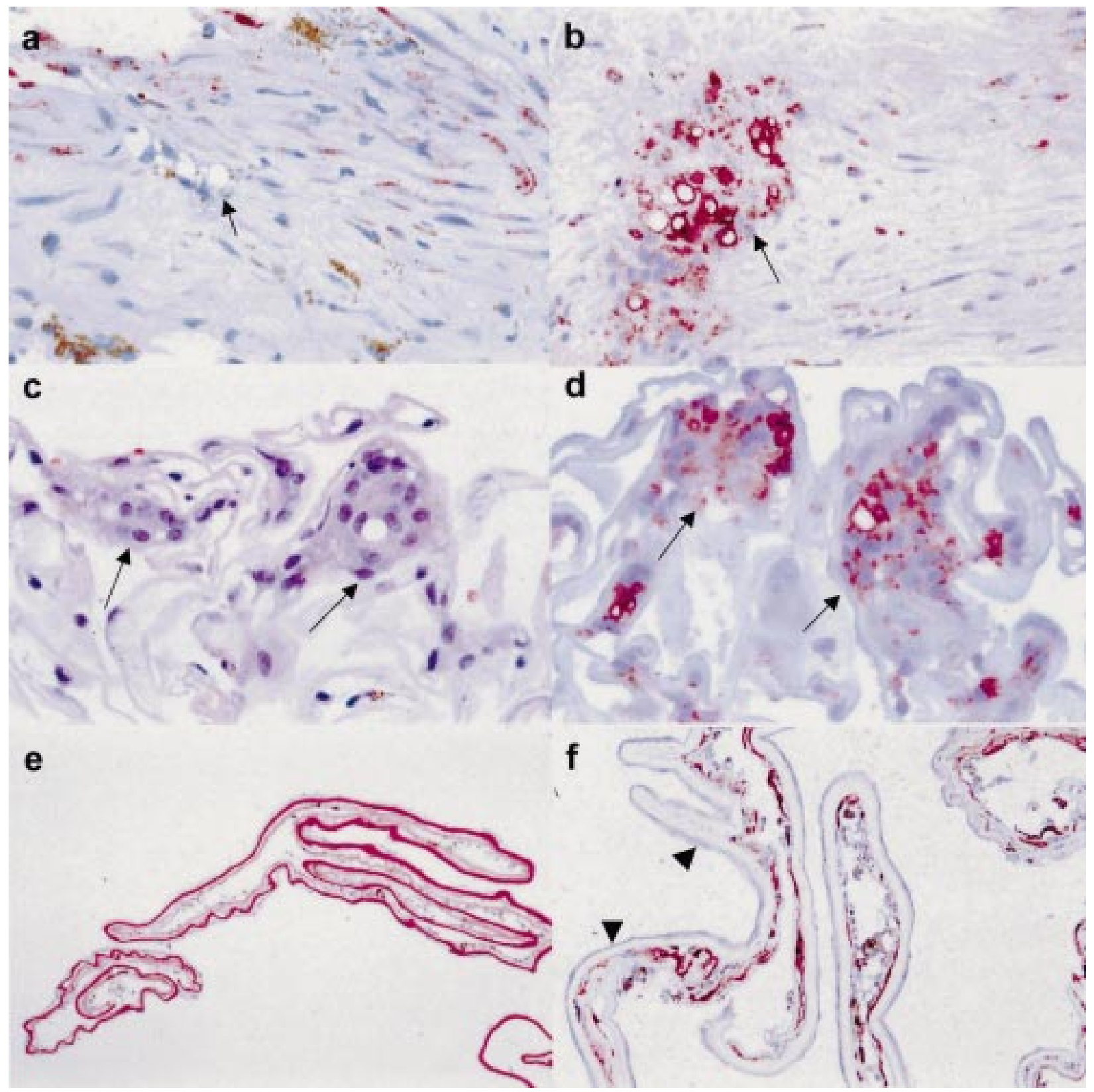

Figure 2 (a-d) Sections of epiretinal membranes and (e and f) of posterior capsule opacification formed in the presence of $F_{6} H_{s}$. (a) and (b) Sections at different levels from the same membrane stained red immunohistochemically for cytokeratins and CD68 respectively (haematoxylin counterstain). Vacuolated cytokeratin negative, CD68 positive cells are present in fibrous component of the specimen (arrows). Note also the presence of pigment and cytokeratin positive fibroblastic cells in (a). (c and d) Sections through this inner limiting lamina-rich membrane stained with haematoxylin and eosin (c) and CD68 (d: immunohistochemical stain, haematoxylin counterstain) demonstrate that the multinucleated cells are CD68 reactive (arrows). (e) Periodic acid Schiff and haematoxylin staining demonstrate that the posterior lens capsule (seen a deep magenta colour) has a delicate cellular proliferation on each surface. $(f)$ Another section from the same specimen as (e) stained red for cytokeratins (haematoxylin counterstain) has a subtle, thin monolayer of fibroblastic lens epithelial cells on one surface of the capsule (arrowheads). On the other (posterior) capsule surface is a membrane containing cytokeratin positive fibroblastic cells, cytokeratin negative vacuolated cells (macrophages), and pigment. Magnification: $a-d \times 300 ; e \times 40 ; f \times 100$. 
served as a major component of retrosilicone oil PVR membranes (that is, membranes forming behind a silicone oil tamponade) and, in this situation, appear distended by spherical, presumed silicone oil-containing intracytoplasmic vacuoles. ${ }^{12}$ However, similar studies on larger numbers of membranes indicate that macrophages (as opposed to cells of RPE origin) may predominate in most retrosilicone oil membranes. ${ }^{13}$ Moreover, it is thought that, in these membranes, the vacuolated cells are chiefly silicone oil laden macrophages. ${ }^{14}$ The vacuolated cells in $\mathrm{F}_{6} \mathrm{H}_{8}$ related PVR membranes are macrophages and also appear to be laden with tamponade agent. In this respect, the histopathology of PVR membranes developing behind $\mathrm{F}_{6} \mathrm{H}_{8}$ is similar to retrosilicone oil membranes.

Silicone oil causes cataract. ${ }^{15}$ Examination of lens capsule from silicone oil filled eyes has revealed silicone laden macrophages adherent to lens capsule. ${ }^{16}$ One of the lens capsules in our study exhibited adherent, presumed $\mathrm{F}_{6} \mathrm{H}_{8}$ laden, macrophages together with RPE and this specimen was the only one of the three capsular biopsies in which the associated lens epithelial cells showed a fibroblastic phenotype. It is interesting to speculate that macrophage and/or RPE derived factors induced the phenotypic shift. However, this retrolental membrane formed in an eye which had initially contained silicone oil. Moreover, the duration of $\mathrm{F}_{6} \mathrm{H}_{8}$ fill was 21 weeks (much longer than in any of the other eyes from which our specimens were obtained). Therefore, it is possible that the lens epithelial changes reflect the extended duration of tamponade.

Although our specimen numbers were too small to confirm any statistical associations, duration of tamponade did not seem to influence the development of multinucleated giant cells within the membranes in the present study. Although such cells are reported in ocular tissues where silicone oil has leaked out of the vitreous cavity, multinucleated giant cells are rarely reported in the silicone oil filled vitreous cavity itself. ${ }^{17}$ The apparent trend for a greater foreign body reaction to $\mathrm{F}_{6} \mathrm{H}_{8}$ than to silicone oil may reflect the lower viscosity of $\mathrm{F}_{6} \mathrm{H}_{8}{ }^{2}$ The low viscosity of $\mathrm{F}_{6} \mathrm{H}_{8}$ would be expected to expedite emulsification. Emulsification of tamponades such as silicone oil has been implicated in supporting macrophage reactions in the vitreous. ${ }^{14}$ Moreover, fluorosilicone oil, which also has a greater emulsification rate than silicone oil, ${ }^{18}$ is suspected of promoting PVR. ${ }^{19}$ Thus, $\mathrm{F}_{6} \mathrm{H}_{8}$ emulsification theoretically might accelerate PVR by inducing macrophage influx and the subsequent accumulation of a wide range of macrophage derived, growth promoting factors. ${ }^{9}$

In conclusion, the histological features of the specimens evaluated in our study are not simply those of PVR. In particular, the macrophagic infiltration suggests that there is a biological response to the novel tamponade agent and this response may be related to a surmised propensity of $\mathrm{F}_{6} \mathrm{H}_{8}$ to emulsify. $\mathrm{F}_{6} \mathrm{H}_{8}$ has promising physical properties as a long term tamponade and further investigations into the pathobiological effects of this agent are warranted. The authors thank Jane Slater and Wendy Gratton for their
help. Our research is funded by the Guide Dogs for the Blind help. Our research is funded by the Guide Dogs for the Blind Association, Engineering and Physical Sciences Research
Council, and the Foundation for the Prevention of Blindness.

1 Fawcett IM, Williams RL, Wong D. Contact angles of substances used for internal tamponade in retinal detachment surgery. Graefes Arch Clin Exp Ophthalmol 1994;232:43844 .

2 Colthurst M, Williams RL, Hiscott P, et al. Biomaterials used in the posterior segment of the eye. Biomaterials 2000; 21:649-65.

3 Kuckelhorn R, Becker J, Zeana D, et al. Long term tolerance of intravitreal semifluorinated alkane in the experimental animal. Ophthalmic Res 1997;29(S1):125.

4 Kirchhof B, Wong D, van Meurs J, et al. The use of semifluorinated alkanes as a long term vitreous substitute. Brf Ophthalmol (in press).

5 Kanawati C, Wong D, Hiscott P, et al. en bloc Dissection of Kanawati C, Wong D, Hiscott $\mathrm{P}$, et al. en bloc Dissection of
epiretinal membranes using aspiration delamination. Eye 1996;10:47-52

6 Hiscott P, Gray R, Grierson I, et al. Cytokeratin-containing cells in proliferative diabetic retinopathy membranes. $\mathrm{Br} \mathcal{F}$ Ophthalmol 1994;78:219-22.

7 Chateris D, Hiscott P, Grierson I, et al. Proliferative vitreoretinopathy: lymphocytes in epiretinal membranes. Ophthalmology 1992;99:1364-7.

8 Hiscott P, Wong D, Grierson I. Challenges in ophthalmic pathology: the vitreoretinal membrane biopsy. Eye 2000;14: 549-59.

9 Hiscott P. Macrophages in the pathobiology of epiretinal membranes: multifunctional cells for a multistage process. Br F Ophthalmol 1993;77:686-7.

10 Machemer R, Laqua H. Pigment epithelial proliferation in retinal detachment (massive periretinal proliferation). Am $\mathfrak{f}$ Ophthalmol 1975;80:1-23.

11 Mueller-Jensen K, Machemer R, Azarnia R. Autotransplantation of retinal pigment epithelial cells in intravitreal diffusion chamber. Am f Ophthalmol 1975;80:530-7.

12 Hiscott P. Vitreoretinale Biopsie brockeliger Membranen unter Silikonol. Klin Monatsbl Augenheilkd 1995;207:317.

13 Heidenkummer HP, Kampik A. Comparative immunohistochemical studies of epiretinal membranes in proliferative vitreoretinal diseases. Fortschr Ophthalmol 1991;88:219-24.

14 Heidenkummer HP, Messmer EM, Kampik A. Recurrent vitreoretinal membranes in intravitreal silicon oil tamponade. Morphologic and immunohistochemical studies. Ophthalmologe 1996;93:121-5.

15 Leaver PK, Grey RHB, Garner A. Complications following silicone-oil injection. Mod Probl Ophthalmol 1979;20:2904.

16 Leaver PK, Grey RHB, Garner A. Silicone oil injection in the treatment of massive preretinal retraction. II. Late complications in 93 eyes. Br 7 Ophthalmol 1979;63:361-7.

17 Parmley VC, Barishak R, Howes EL, et al. Foreign-body giant cell reaction to liquid silicone. Am $\mathcal{F}$ Ophthalmol 1986;101:680-3.

18 Giordano GG, Refojo MF. Silicone oils as vitreous substitutes. Prog Polym Sci 1998;23:509-32.

19 Petersen J, Ritzau-Tondrow U, Vogel M. Fluorosilicone oil heavier than water: a new aid in vitreoretinal surgery. Klin Monatsbl Augenheilkd 1986;189:228-32.

20 Machemer R, Aaberg TM, Freeman HM, et al. An updated classification of retinal detachment with proliferative vitreoretinopathy. Am f Ophthalmol 1991;112:159-65. 